\title{
The role of dermoscopy in a topical steroid-damaged face
}

\author{
Sidharth Sonthalia ${ }^{1}$, Abhijeet K. Jha ${ }^{2}$, Reena Sharma ${ }^{3}$
}

1 SKINNOCENCE: The Skin Clinic, Guragaon, India
2 Patna Medical College and Hospital, Patna, Bihar, India
3 Department of Dermatology, Derma Essence Clinic, Noida, India

Key words: dermoscopy, steroid abuse, topical steroid-damaged face

Citation: Sonthalia S, Jha AK, Sharma R. The role of dermoscopy in a topical steroid-damaged face. Dermatol Pract Concept. 2018;8(3):166167. DOI: https://doi.org/10.5826/dpc.0803a02

Received: February 8, 2018; Accepted: April 21, 2018; Published: July 31, 2018

Copyright: $@ 2018$ Sonthalia et al. This is an open-access article distributed under the terms of the Creative Commons Attribution License, which permits unrestricted use, distribution, and reproduction in any medium, provided the original author and source are credited.

Funding: None.

Competing interests: The authors have no conflicts of interest to disclose.

All authors have contributed significantly to this publication.

Corresponding author: Sidharth Sonthalia, SKINNOCENCE: The Skin Clinic, C-2246, Sushant Lok-1, Block C, Gurgaon, 122009, India. Email: sidharth.sonthalia@gmail.com

A 29-year old male presented with pinkish-red erythema over the cheeks with patchy brown discoloration and grossly visible telangiectasias of 6 months' duration (Figure 1). He also complained about his facial skin being very sensitive, especially to sun exposure. The patient was aware that he had melasma and gave a history of occasional use of sunscreen in the past. Despite repeated and persuasive questioning, he staunchly denied applying any topical steroid-containing formulations or depigmenting creams. Polarized dermoscopic examination (EScope; Nakoda, $\times 20$ ) of the cheeks revealed a reddish-brown background, brown dots, globules and clods, multiple tortuous and branching linear vessels and telangiectasias, and ivory white-to-strawberry ice cream colored patches in addition to conspicuous hypertrichosis (Figure 2A-2B). Suspecting topical steroid abuse, he was shown the dermoscopic features on the computer screen and cautioned about the complications of "topical steroid-damaged face." He finally admitted to having used a mometasonecontaining triple combination cream over the cheeks twice a day for the previous 4 months, at the suggestion of a friend. Since his last examination, the patient has been using a broadspectrum sunscreen on a daily basis, topical vitamin $20 \%$

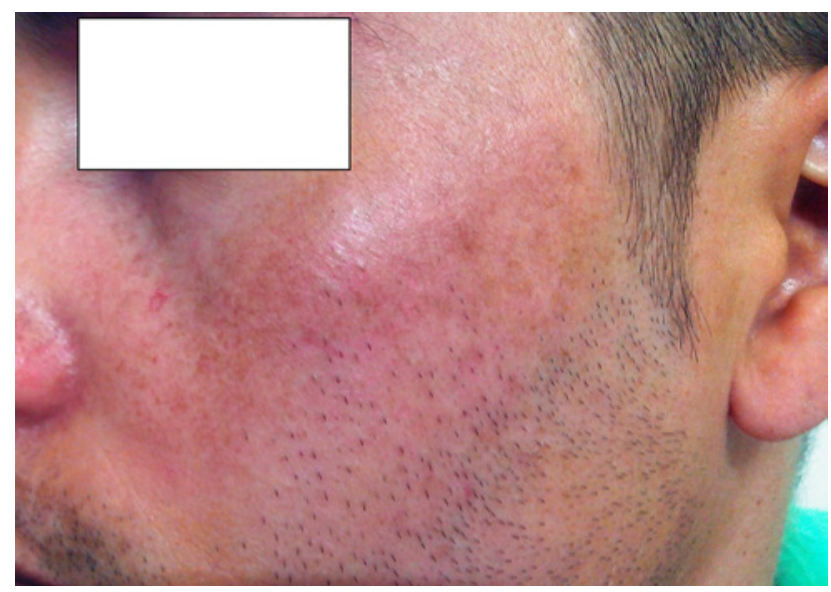

Figure 1. Clinical picture of the patient showing pinkish-red erythema over the cheeks with patchy brown discoloration and grossly visible telangiectasias. [Copyright: (O2018 Sonthalia et al.]

serum and has been scheduled for intense pulsed light therapy for facial rejuvenation.

Prominent telangiectasias, ivory white-to-strawberrycolored patches (suggestive of skin atrophy) and lesional hypertrichosis constitute dermoscopic features which are 

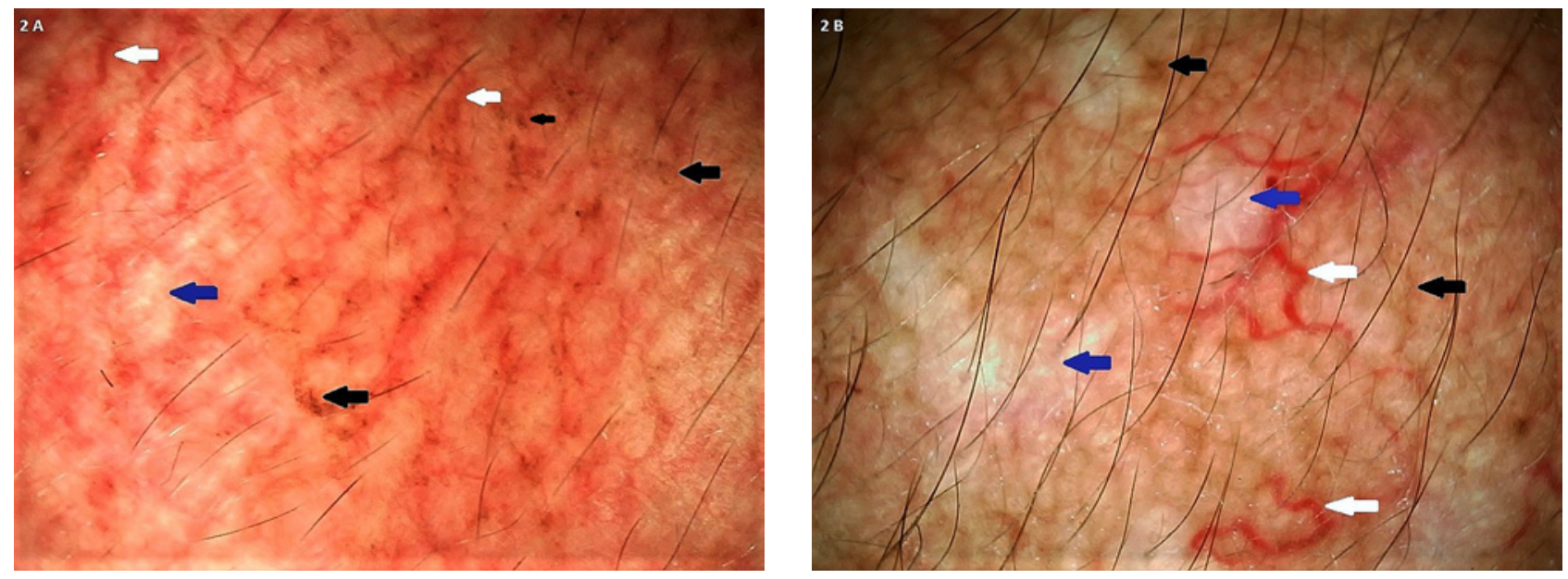

Figure 2. (A, B) Dermoscopy of the cheek revealing reddish-brown background, brown dots, globules and clods (black arrows) suggestive of a background of melasma, multiple tortuous and branching linear vessels (white arrows), telangiectasias and ivory white-to-strawberrycolored patches (blue arrow) suggestive of skin atrophy, in addition to conspicuous hypertrichosis (Escope, videodermoscope, polarizing mode, 20x). [Copyright: (C2018 Sonthalia et al.]

indicative of "topical steroid-damaged face," while the brown pigmented structures suggest a background of melasma. The abuse of topical steroid-containing formulations over the face has now been well established as a dermatological nuisance in India [1].

\section{Conclusions}

Through this report, we wish to highlight that many of these patients are in a denial about their steroid abuse. Importantly, dermoscopy not only noninvasively confirms the suspicion, but also aids in the patient's understanding of the seriousness of topical steroid abuse through the demonstration of pictures explained in patient-friendly language. In the majority of cases it also ensures further steroid abuse and improves treatment compliance [2].

\section{References}

1. Coondoo A, Phiske M, Verma S, Lahiri K. Side-effects of topical steroids: A long overdue revisit. Indian Dermatol Online J. 2014;5(4):416-425.

2. Sonthalia S, Errichetti E. Dermoscopy—not just for diagnosis and not just for Dermatologists! Kathmandu Univ Med J (KUMJ). 2017;15(57):1-2. 